\title{
Glucagon-like peptide-2 enhances intestinal epithelial barrier function of both transcellular and paracellular pathways in the mouse
}

\author{
M A Benjamin, D M McKay, P-C Yang, H Cameron, M H Perdue
}

\begin{abstract}
Background and aims-Glucagon-like peptide-2 (GLP-2) is a recently identified potent intestinotrophic factor. We have evaluated the effect of GLP-2 treatment on intestinal epithelial barrier function in mice.

Methods-CD-1 mice were injected subcutaneously with GLP-2 or a protease resistant analogue, $h\left[\mathrm{Gly}^{2}\right] \mathrm{GLP}-2$, twice daily for up to 10 days. Saline injected mice served as controls. Jejunal segments were mounted in Ussing chambers. Tissue conductance was measured and unidirectional fluxes were determined for (i) $\mathrm{Na}^{+}$ and the small inert probe Cr-EDTA (both transported via the paracellular pathway) and (ii) the macromolecule horseradish peroxidase (HRP, transported via the transcellular pathway).

Results-Mice treated with GLP-2 or h[Gly $\left.{ }^{2}\right]$ GLP-2 for 10 days demonstrated significantly reduced intestinal conductance and fluxes of $\mathrm{Na}^{+}, \mathrm{Cr}-\mathrm{EDTA}$, and HRP. Electron microscopy confirmed that GLP-2 reduced endocytic uptake of HRP into enterocytes. Functional changes (evident by four hours) preceded morphological changes (evident by 48 hours).

Conclusions-GLP-2 enhances intestinal epithelial barrier function by affecting both paracellular and transcellular pathways and thus may be of therapeutic value in a number of gastrointestinal conditions.
\end{abstract}

(Gut 2000;47:112-119)

Keywords: intestinal permeability; macromolecular transport; growth factors

Intestinal Disease Research Program, McMaster University, Hamilton, Ontario, Canada

M A Benjamin

D M McKay

P-C Yang

H Cameron

M H Perdue

Correspondence to:

Dr M Perdue, HSC-3N5C,

McMaster University, 1200

Main Street West, Hamilton,

ON, Canada, L6J 3X6.

Email:

perdue@fhs.mcmaster.ca

Accepted for publication 21 December 1999 and/or bacterial products into the mucosa may trigger inflammatory reactions with release of cytokines and bioactive mediators resulting in intestinal damage and dysfunction.

Animal models and epithelial cell culture studies have demonstrated that many factors are capable of increasing intestinal epithelial permeability. Such factors include the nutritional status of the host,${ }^{5}$ certain medications, ${ }^{6}$ stress, ${ }^{7}$ bacterial infections and/or toxins, ${ }^{8-10}$ and immune cell cytokines (for example interferon $\gamma,{ }^{11}$ tumour necrosis factor $\alpha,{ }^{1213}$ and interleukin $4^{14}{ }^{15}$ ). Although it is clear that a number of stimuli can elicit greater gastrointestinal permeability, less is known about factors that maintain or enhance the barrier function of the intestinal epithelium. Growth factors, including transforming growth factor $\beta,{ }^{16}{ }^{17}$ insulin-like growth factor- $1,{ }^{18}$ and epidermal growth factor ${ }^{19}{ }^{20}$ are capable of maintaining or restoring intestinal mucosal integrity thereby fostering healing and restitution. However, most growth factors are not organ specific and induce additional non-specific changes that can affect homeostasis.

In 1971, Gleeson et al described a glucagon secreting endocrine tumour capable of inducing intestinal hyperplasia. ${ }^{21}$ More recent investigations have shown that a cleavage product of the molecule, designated glucagon-like peptide-2 (GLP-2), is a trophic factor specific for the bowel. Thus in mice, twice daily treatment with low doses of GLP-2 resulted in increased gut weight and villus height in the small intestine but did not affect the thickness of the smooth muscle layer. ${ }^{22}$ Concomitant with the change in gut architecture was an increase in disaccharidase levels and increased nutrient absorption. ${ }^{23}$

Despite the recognition that GLP-2 stimulates small intestinal growth, the relationship between this novel growth factor and intestinal barrier function has not been reported. Therefore, the primary aim of this study was to determine the ability of GLP-2 and a protease resistant analogue to regulate the barrier function of the murine small intestine. Our data illustrate that GLP-2 significantly reduces paracellular transport of ions and small molecules, and moreover dramatically inhibits endocytic uptake of macromolecules. These findings support the postulate that GLP-2 treatment may be an effective therapy for

Abbreviations used in this paper: GLP-2, glucagon-like peptide-2; HRP, horseradish peroxidase; Isc, short circuit current; PBS, phosphate buffered saline. 
enhancing, maintaining, or recovering normal barrier function in intestinal disease.

\section{Methods}

ANIMALS

Female CD-1 mice (eight weeks of age, mean weight $30 \mathrm{~g})$ were obtained from Harlan Sprague-Dawley Inc. (Indianapolis, Indiana, USA). Mice were not restricted by diet or activity during the experiment. After one week of acclimatisation, mice were matched by weight and allocated to one of three groups. Mice were injected subcutaneously twice daily for 10 consecutive days with $5 \mu \mathrm{g}$ of either native human GLP-2 or a synthetic protease resistant human analogue h[Gly $\left.{ }^{2}\right] \mathrm{GLP}-2$ (donated by Allelix Biopharmaceuticals Inc., Mississauga, Ontario, Canada). ${ }^{2}$ This dose was chosen based on pilot studies with native GLP-2 which showed that it produced consistent, significantly increased mucosal growth. Controls were injected with the vehicle (phosphate buffered saline (PBS)). Experiments were conducted on day 11 when mice were weighed and sacrificed by cervical dislocation. The small intestine was removed, flushed with cold saline, blot dried, and weighed. The jejunum was divided into segments for morphometric assessment, protein determination, and Ussing chamber studies. To obtain information on the timing of effects, additional experiments were conducted in mice injected once with $\mathrm{h}\left[\mathrm{Gly}^{2}\right] \mathrm{GLP}-2$ and studied at four hours and in mice injected twice a day for two days and studied at 48 hours. The studies described in this paper were conducted with approval from the McMaster University Animal Care Committee.

\section{MORPHOLOGY}

Light microscopy

A $1 \mathrm{~cm}$ segment of intestine $(\sim 10 \mathrm{~cm}$ from the pylorus) was opened along the mesenteric border and immersion flat fixed in 10\% neutral buffered formalin. After dehydration and wax embedding, tissue sections were stained with haematoxylin and eosin. Mucosal height, villus length, and crypt depth were measured in coded sections (8-10 intact villus-crypt units per mouse) by a single investigator (MAB), who was unaware of the mouse treatment, using a calibrated eyepiece. The villus:crypt ratio was subsequently calculated.

\section{Electron microscopy}

An additional $1 \mathrm{~cm}$ segment (distal to that taken for light microscopy) was immediately fixed with $2 \%$ glutaraldehyde in $0.1 \mathrm{~mol} / 1$ sodium cacodylate buffer for two hours at room temperature, transferred to sodium cacodylate buffer, and stored at $4^{\circ} \mathrm{C}$ overnight. Tissues were subsequently processed for routine electron microscopy. Photomicrographs of well orientated epithelial cells from the mid villus region were prepared. Using a computer supported image analysis system (Mop Videoplan, Kontron, Germany) one investigator (PCY), who was unaware of the mouse treatment, analysed 12 coded photomicro- graphs per group and measured enterocyte width and length, and microvillus length.

MUCOSAL PROTEIN

A $7 \mathrm{~cm}$ segment of small intestine (proximal to that used for morphology) was removed and the mucosal layer was scraped off between two glass slides. The mucosal scraping was weighed and buffer was added at a concentration of $10 \mathrm{ml} / \mathrm{g}$ tissue. The mucosal suspension was homogenised on ice for 30 seconds, snap frozen in liquid nitrogen, and stored at $-20^{\circ} \mathrm{C}$ before determination of protein content. ${ }^{24}$

USSING CHAMBER STUDIES

A $12 \mathrm{~cm}$ segment of small intestine (distal to that used for morphology) was opened along the mesenteric border and cut into four flat sheets. Full thickness segments (devoid of Peyer's patches) were mounted in modified Ussing chambers and bathed with oxygenated Krebs buffer that contained (in $\mathrm{mM}$ ): $115 \mathrm{NaCl}, 1.25$ $\mathrm{CaCl}_{2}, 1.2 \mathrm{MgCl}_{2}, 2.0 \mathrm{KH}_{2} \mathrm{PO}_{4}$, and 25 $\mathrm{NaHCO}_{3}, \mathrm{pH} 7.35 \pm 0.02$, at $37^{\circ} \mathrm{C}$. In addition, the serosal buffer contained $10 \mathrm{mM}$ glucose as an energy source balanced by $10 \mathrm{mM}$ mannitol in the mucosal buffer. Glucose was not added to the mucosal buffer as we were interested specifically in permeability rather than glucose linked ion transport. Tissues were short circuited at zero volts using a World Precision Instruments automated voltage clamp (Narco Scientific, Mississauga, Ontario, Canada). ${ }^{25}$ Conductance $(\mathrm{G})$ was calculated according to Ohm's law using potential difference and short circuit current (Isc) values. Tissues with abnormally high initial conductance values $\left(>40 \mathrm{mS} / \mathrm{cm}^{2}\right)$ or whose conductance increased during the course of the experiment (calculated every 15 minutes) were considered damaged and were excluded from subsequent analysis.

\section{(a) Flux of $\mathrm{Na}^{+}$}

The unidirectional serosal-to-mucosal flux of $\mathrm{Na}^{+}$was determined as an indication of passive ion permeability via the paracellular pathway. Flux was measured under voltage clamped conditions by adding $10 \mu \mathrm{Ci}$ of ${ }^{22} \mathrm{Na}^{+}$(New England Nuclear, Lachine, Quebec, Canada) to the serosal buffer. Following a 20 minute equilibration period, $1 \mathrm{ml}$ samples from the "cold" buffer and $50 \mu \mathrm{l}$ samples from the "hot" buffer were collected and replaced with the appropriate volume of buffer every 15 minutes. Radioactivity was measured in a gamma counter and flux (in $\mu \mathrm{mol} / \mathrm{cm}^{2} / \mathrm{h}$ ) was calculated.

\section{(b) Flux of Cr-EDTA}

Cr-EDTA is generally considered to be a marker of paracellular permeability. ${ }^{1}$ Transepithelial flux of this small $(360 \mathrm{Da})$ inert probe was determined as described previously ${ }^{13}$ using the same approach as that for the radiolabelled ion. ${ }^{51} \mathrm{Cr}$-EDTA $(6 \mu \mathrm{Ci} / \mathrm{ml}$; Radiopharmacy, Chedoke-McMaster Hospital, Hamilton, Ontario, Canada) was added to the mucosal buffer bathing jejunal segments mounted in Ussing chambers. Non-radioactive Cr-EDTA was 
added to the serosal buffer at an equal concentration. Samples were obtained as above, counted, and flux expressed in $\mathrm{nmol} / \mathrm{cm}^{2} / \mathrm{h}$.

(c) Flux of horseradish peroxidase (HRP)

The transcellular passage of HRP (44000 Da), a model protein antigen, ${ }^{25}$ was determined by flux and electron microscopy (see below) as previously described. ${ }^{26}$ Type VI HRP (SigmaAldrich Canada Inc., Oakville, Ontario, Canada) was added to the mucosal buffer at a concentration of $10^{-5} \mathrm{M}$. Samples were obtained at intervals as above. The sample (appropriately diluted) was then mixed with a reaction solution containing hydrogen peroxide and $o$-dianisidine (Sigma-Aldrich Canada Inc.), and the rate of appearance of the reaction product was determined at $460 \lambda$. Flux was expressed as $\mathrm{pmol} / \mathrm{cm}^{2} / \mathrm{h}$.

(d) Quantification of HRP containing endosomes in enterocytes.

Following exposure of the intestine in Ussing chambers to luminal HRP for 60 minutes, the segment was removed and immersed in $2 \%$ glutaraldehyde in $0.1 \mathrm{~mol} / 1$ sodium cacodylate buffer for two hours at room temperature, transferred to sodium cacodylate buffer, and stored at $4^{\circ} \mathrm{C}$ overnight. The tissue was washed three times in $0.05 \mathrm{~mol} / 1$ Tris buffer and then incubated for 30 minutes in $5 \mathrm{mg}$ of 3,3'diaminobenzadine tetrahydrochlorine (SigmaAldrich Canada Inc.) in $10 \mathrm{ml}$ of $0.05 \mathrm{~mol} / 1$ Tris buffer and $0.01 \%$ hydrogen peroxide. The tissue was subsequently processed for electron microscopy and photomicrographs prepared of well oriented epithelial cells. The area occupied by HRP product containing endosomes located within a $112 \mu \mathrm{m}^{2}$ window in the apical region of the enterocyte above the nucleus was measured in coded photomicrographs by one of the investigators (PCY) using a computer supported image analysis system. A total of 12 windows for each of four mice per group (48 enterocytes) were analysed.

(e) Effect of in vitro addition of GLP-2.

GLP-2 (5-1000 $\mathrm{nM}$ ) was added to the luminal or serosal side of intestinal segments from naïve mice and $\mathrm{G}$ and Isc values were monitored over a 90 minute period.

STATISTICAL ANALYSES

Statistical analyses were performed using one way analysis of variance followed by NewmanKeuls multiple comparisons test. Student's $t$ test was used for individual comparisons. Data are expressed as mean (SEM).

\section{Results}

INTESTINAL CHARACTERISTICS

Weight and protein

Treatment of mice with GLP-2 or $\mathrm{h}\left[\mathrm{Gly}^{2}\right] \mathrm{GLP}-2$ twice daily for 10 consecutive days significantly $(\mathrm{p}<0.001)$ increased gut weight when expressed either as absolute values or as per cent of body weight. Gut wet weight was $122 \%$ or $140 \%$ of control values in mice treated with GLP-2 or h[Gly $\left.{ }^{2}\right]$ GLP-2, respectively (fig $1 \mathrm{~A}$ ). h[Gly $\left.{ }^{2}\right] \mathrm{GLP}-2$ was sig-
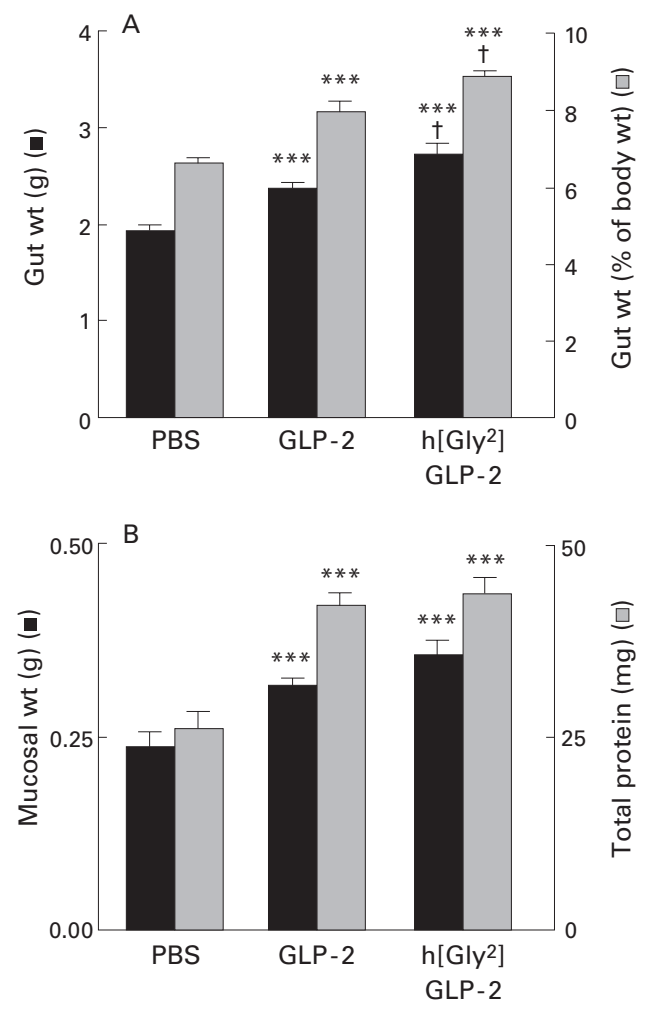

Figure 1 (A) Effect of GLP-2 or $h\left[G l y^{2}\right] G L P-2$

treatment (5 $\mu \mathrm{g}$ injected on each of 10 days in mice) on wet weight of the small intestine or small intestinal weight as a percentage of body weight. (B) Effect of GLP-2 or

$h\left[G y^{2}\right] G L P-2$ treatment for 10 days on weight of mucosal scrapings and protein content from a fixed length segment of murine intestine. Values are mean (SEM); $n=7-8$ micelgroup. ${ }^{\star * \star} p<0.001$ compared with control (phosphate buffered saline (PBS) treated mice); $t p<0.05$ compared with GLP-2 treated mice.

nificantly $(p<0.05)$ more effective than GLP-2. Figure $1 \mathrm{~B}$ illustrates that the weight of mucosal scrapings was increased by $33 \%$ or $50 \%$ following treatment with GLP-2 or $\mathrm{h}\left[\mathrm{Gly}^{2}\right] \mathrm{GLP}-2$, respectively. In addition, GLP-2 or h[Gly $\left.{ }^{2}\right]$ GLP-2 resulted in a significant $(p<0.001)$ increase in mucosal protein compared with control values (from 26.5 (2.2) to 42.4 (1.7) or 43.9 (2.4) $\mathrm{mg}$, respectively; $\mathrm{n}=7-8 \mathrm{mice} /$ group).

\section{Morphology}

Morphometric analysis of histological sections revealed that GLP-2 treatment of mice for 10 days increased both the total mucosal thickness and villus height by approximately $25 \%$ compared with control values (table 1). Mice treated with $\mathrm{h}\left[\mathrm{Gly}^{2}\right] \mathrm{GLP}-2$ displayed a $35 \%$ increase in total mucosal thickness and villi were $40 \%$ longer than in control (PBS treated) mice (table 1). Neither experimental treatment caused any consistent or significant change in crypt depth. As a consequence of villus elongation, there was a shift in the villus:crypt ratio that was statistically significant $(\mathrm{p}<0.05)$, from 5.12 (0.37) (control) to $6.18(0.31)$ or $7.23(0.41)$ for treatment with GLP-2 or h[Gly $\left.{ }^{2}\right] \mathrm{GLP}-2$, respectively ( $\mathrm{n}=7-8 \mathrm{mice} / \mathrm{group})$. Electron microscopy demonstrated that GLP-2 or h[Gly $\left.{ }^{2}\right]$ GLP-2 treatment changed the shape of the epithelial cells causing them to become narrower and 
Table 1 Effect of GLP-2 or h[Gly $]$ GLP-2 treatment for 10 days on morphology

\begin{tabular}{lllllll}
\hline Mouse treatment & $\begin{array}{l}\text { Mucosal height } \\
(\mu m)\end{array}$ & $\begin{array}{l}\text { Villus length } \\
(\mu m)\end{array}$ & $\begin{array}{l}\text { Crypt depth } \\
(\mu m)\end{array}$ & $\begin{array}{l}\text { Microvillus length } \\
(\mu m)\end{array}$ & $\begin{array}{l}\text { Enterocyte width } \\
(\mu m)\end{array}$ & $\begin{array}{l}\text { Enterocyte length } \\
(\mu m)\end{array}$ \\
\hline PBS & $653(33)$ & $541(31)$ & $114(5)$ & $1.20(0.08)$ & $5.17(0.20)$ & $17.57(0.47)$ \\
GLP-2 & $816(26)^{\star}$ & $688(28)^{\star}$ & $121(6)$ & $2.27(0.07)^{\star}$ & $4.83(0.22)$ & $29.00(0.43)^{\star}$ \\
h[Gly ${ }^{\star}$ GLP-2 & $880(22)^{\star}$ & $762(22)^{\star}$ & $118(6)$ & $2.31(0.11)^{\star} \dagger$ & $4.19(0.16)^{\star} \dagger$ & $32.75(0.40)^{\star} \dagger$ \\
\hline
\end{tabular}

Mice were injected daily with $5 \mu \mathrm{g}$ of GLP-2 or its analogue (h[Gly $\left.{ }^{2}\right] \mathrm{GLP}-2$ ) for 10 days.

All measurements are expressed in $\mu \mathrm{m}$. Values are mean (SEM); $=7-8$ mice per group.

EM measurements were made on 12 photomicrographs per group.

${ }^{\star} \mathrm{p}<0.05$ compared with phosphate buffered saline (PBS) treated mice (control); $\nmid \mathrm{p}<0.05$ compared with GLP- 2 treated mice.

longer than control enterocytes (table 1; fig 2A, USSING CHAMBER STUDIES

B). Microvilli were also longer (table 1; fig 2C, Paracellular permeability

D). Again, h[Gly $\left.{ }^{2}\right]$ GLP-2 was more effective Treatment of mice with either GLP-2 or than GLP-2 in altering enterocyte morphology. h[Gly $\left.{ }^{2}\right]$ GLP-2 for 10 days significantly de-
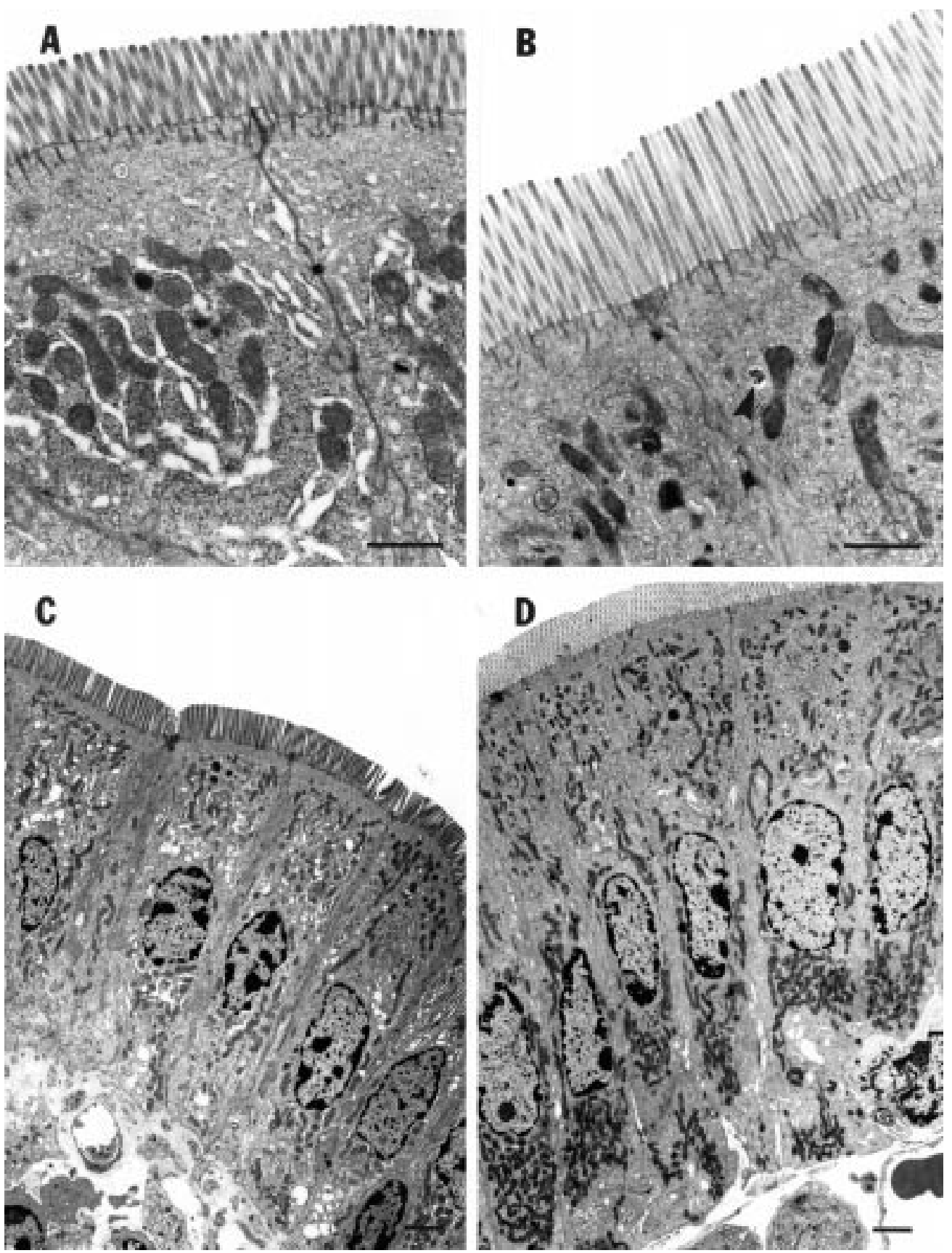

Figure 2 Representative photomicrographs of murine intestinal enterocytes. $(A)$ and $(C)$ are from phosphate buffered saline (PBS) treated mice (control); (B) and (D) are from mice after 10 days of treatment with h[Gly $\left.{ }^{2}\right] G L P-2(5 \mu g)$. Note the longer microvilli in $h\left[G l y^{2}\right] G L P-2$ treated mice (B) compared with controls $(A)$ (bar=200 $\mu m$ ). The arrowhead in (B) indicates an endosome containing HRP. Note the increased cell length in $h\left[G l y^{2}\right] G L P-2$ treated mice (D) compared with controls $(C)$ (bar=100 $\mu \mathrm{m})$. 

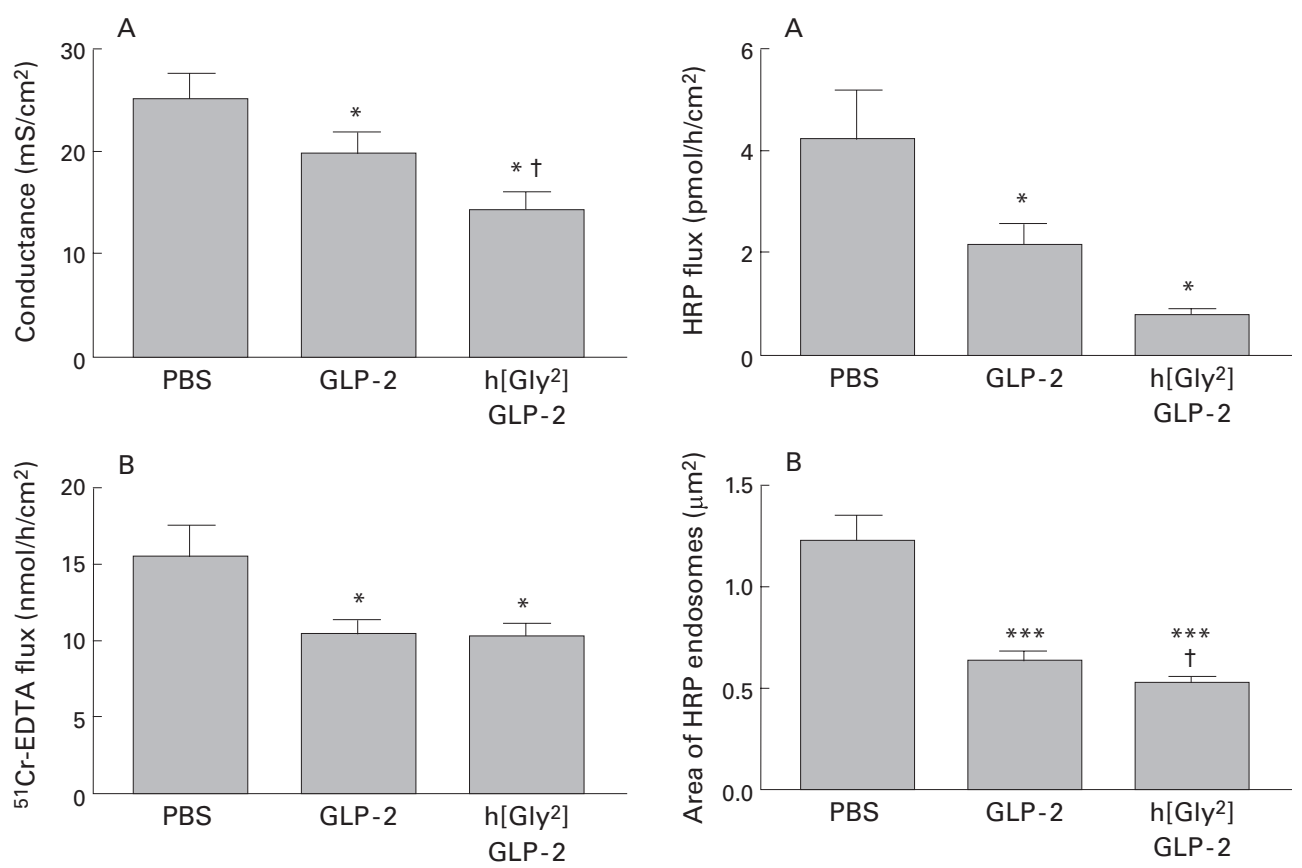

Figure 3 Effect of GLP-2 or $h\left[G l y^{2}\right] G L P-2$ treatment (5 $\mu \mathrm{g}$ injected on each of 10 days in mice) on $(A)$ transepithelial ion conductance and (B) flux of ${ }^{51} C r$-EDTA across jejunal segments. Values are mean (SEM). (A) $n=30-31$ tissues from eight mice per group. (B) $n=14-16$ tissues from four mice per group. ${ }^{\star} p<0.05$ compared with control (phosphate buffered saline (PBS) treated mice); $t p<0.05$ compared with GLP-2 treated mice.

creased the conductance of jejunal tissues by approximately $25 \% \quad(\mathrm{p}<0.05) \quad$ or $45 \%$ $(\mathrm{p}<0.01)$, respectively (fig $3 \mathrm{~A})$. Isc also tended to be lower in treated mice although values were not significantly different $(38.2(2.0)$ in tissues from controls $v 34.1$ (2.6) in tissues from GLP-2 treated mice and 32.7 (2.1) in tissues from $\mathrm{h}\left[\mathrm{Gly}^{2}\right] \mathrm{GLP}-2$ treated mice; $\mathrm{n}=14-31$ tissues/group). The flux of the small inert probe, Cr-EDTA, was significantly reduced by approximately $35 \%(p<0.05)$ across the intestine in mice treated with GLP-2 or $\mathrm{h}\left[\mathrm{Gly}^{2}\right] \mathrm{GLP}-2$ compared with intestinal tissue from control mice (fig 3B). In addition, $\mathrm{h}\left[\mathrm{Gly}^{2}\right] \mathrm{GLP}-2$ peptide treatment reduced the serosal-to-mucosal flux of $\mathrm{Na}^{+}$by approximately $35 \%(\mathrm{p}<0.05)$ from $11.5(0.8)$ to 7.7 (0.6) $\mu \mathrm{mol} / \mathrm{h} / \mathrm{cm}^{2}$ ( $\mathrm{n}=8$ tissues/group). Taken together, these findings indicate a reduced ability of ions and small molecules to permeate through the paracellular pathway.

Acute addition of GLP-2 (5-1000 nM) to tissues in chambers produced no significant change in conductance or Isc within 90 minutes compared with control tissues to

Figure 4 Effect of GLP-2 or h[Gly $]$ GLP-2 treatment (5 $\mu \mathrm{g}$ injected on each of 10 days in mice) on macromolecular permeability measurements following luminal addition of horseradish peroxidase (HRP $\left.10^{-5} \mathrm{~mol} / \mathrm{l}\right)$. (A) Flux of HRP across jejunal segments. Values are mean (SEM) $n=12-15$ tissues from $4-5$ mice per group. ${ }^{*} p<0.05$ compared with control mice. (B) Area of HRP containing endosomes in enterocytes 60 minutes after HRP addition. Values are mean (SEM); $n=12$ photomicrographs per mouse, four mice per group (48 enterocytes). $\star_{\star \star} p<0.001$ compared with control (phosphate buffered saline (PBS) treated mice); $t p<0.05$ compared with GLP-2 treated mice.

which vehicle was added ( $\mathrm{G}$ values ranged from $20.2(1.7)$ to $24.2(1.9) \mathrm{mS} / \mathrm{cm}^{2}$ and Isc from 34.5 (2.1) to $37.7(2.2) \mu \mathrm{A} / \mathrm{cm}^{2} ; \mathrm{n}=8-10$ tissues/group).

\section{Transcellular permeability}

The flux of HRP across mouse intestine was significantly $(\mathrm{p}<0.05)$ reduced by approximately $50 \%$ from control values (fig $4 \mathrm{~A}$ ). An even more dramatic decrease $(\mathrm{p}<0.001)$ in HRP transport $(\sim 80 \%)$ was induced by treating mice with $\mathrm{h}\left[\mathrm{Gly}^{2}\right] \mathrm{GLP}-2$. Electron microscopy demonstrated that the pathway for HRP transport was transcellular in that HRP was evident within endosomes but not in the paracellular regions (fig $2 \mathrm{~B}$ ). There was a significant diminution $(>50 \%)$ in the area of HRP containing endosomes in jejunal enterocytes of both GLP-2 and h[Gly $\left.{ }^{2}\right]$ GLP-2 treated mice compared with control values (fig $4 \mathrm{~B}$ ). Again, $\mathrm{h}\left[\mathrm{Gly}^{2}\right] \mathrm{GLP}-2$ was significantly $(\mathrm{p}<0.05)$ more effective than GLP-2.

Table 2 Effect of $h\left[G l y^{2}\right] G L P-2$ treatment for four or 48 hours on intestinal weight and morphology

\begin{tabular}{lllllll}
\hline Mouse treatment & $\begin{array}{l}\text { Gut weight } \\
(\mathrm{g})\end{array}$ & $\begin{array}{l}\text { Mucosal protein } \\
(\mathrm{mg})\end{array}$ & $\begin{array}{l}\text { Villus height } \\
(\mathrm{mm})\end{array}$ & $\begin{array}{l}\text { Enterocyte width } \\
(\mathrm{mm})\end{array}$ & $\begin{array}{l}\text { Enterocyte length } \\
(\mathrm{mm})\end{array}$ & $\begin{array}{l}\text { MV length } \\
(\mathrm{mm})\end{array}$ \\
\hline PBS & $1.81(0.05)$ & $26.4(2.0)$ & $521(25)$ & $5.6(0.2)$ & $20.6(0.8)$ & $1.15(0.05)$ \\
h[Gly ${ }^{2}$ GLP-2 $(4 \mathrm{~h})$ & $1.80(0.03)$ & $27.2(1.7)$ & $512(14)$ & $5.5(0.2)$ & $23.4(0.6)$ & $1.15(0.06)$ \\
h[Gly $]$ GLP-2 $(48 \mathrm{~h})$ & $1.76(0.06)$ & $28.4(3.0)$ & $530(17)$ & $5.0(0.2)$ & $31.6(0.9)^{\star}$ & $1.60(0.06)^{\star}$
\end{tabular}

Mice were injected either once (four hour group) or daily for two days (48 hour group) with $5 \mu \mathrm{g}$ of h[Gly $\left.{ }^{2}\right] \mathrm{GLP}-2$.

Values are mean (SEM); $n=5$ mice per group.

EM measurements were made on 12 photomicrographs per group; MV, microvilli.

${ }^{\star} \mathrm{p}<0.05$ compared with phosphate buffered saline (PBS) treated mice (control). 
Table 3 Effect of $h\left[G y^{2}\right] G L P-2$ treatment for four or 48 hours on intestinal permeability parameters

\begin{tabular}{llllrll}
\hline Mouse treatment & $G\left(\mathrm{mS} / \mathrm{cm}^{2}\right)$ & $n$ & $\begin{array}{l}\text { Cr-EDTA flux } \\
(\text { mmol/h/cm }\end{array}$ & $n$ & $\begin{array}{l}\text { HRP flux } \\
(\text { pmol/h/cm }\end{array}$ & $n$ \\
\hline PBS & $29.8(0.8)$ & 81 & $15.5(1.1)$ & 31 & $3.8(0.5)$ & 33 \\
h[Gly ${ }^{2}$ GLP-2 (4h) & $25.7(1.7)^{\star}$ & 23 & $10.2(0.4)^{\star}$ & 9 & $1.6(0.2)^{\star \star}$ & 13 \\
h[Gly ${ }^{2}$ GLP-2 $(48 \mathrm{~h})$ & $25.7(1.4)^{\star}$ & 20 & $11.7(0.8)^{\star}$ & 11 & $1.3(0.4)^{\star \star}$ & 12
\end{tabular}

Mice were injected either once (four hour group) or daily for two days (48 hour group) with $5 \mu \mathrm{g}$ of h[Gly $\left.{ }^{2}\right] \mathrm{GLP}-2$.

Values are mean (SEM); $\mathrm{n}$ is the number of tissues studied from six mice for $\mathrm{h}\left[\mathrm{Gly}^{2}\right] \mathrm{GLP}-2$ or 33 phosphate buffered saline (PBS) treated mice (control) (combined from all experiments).

${ }^{\star} \mathrm{p}<0.05,{ }^{\star \star} \mathrm{p}<0.01$ compared with PBS treated control mice.

STUDIES OF EARLY TIME POINTS

To determine if GLP-2 induced enhancement of the epithelial barrier was due to increased growth and morphological characteristics (longer cells, more densely packed) of epithelial cells, additional studies were performed at earlier time points. At four and 48 hours after treatment with $\mathrm{h}\left[\mathrm{Gly}^{2}\right] \mathrm{GLP}-2$, there were no significant changes in gut weight, mucosal protein, mucosal thickness, or villus height (table 3). However, epithelial cells and microvilli were longer at 48 hours (but not at four hours), with cell length similar to that after 10 days of treatment. In contrast, tissue conductance was significantly reduced $(\mathrm{p}<0.05)$ at both four and 48 hours, and the flux of Cr-EDTA was also significantly decreased $(\mathrm{p}<0.05)$ from 15.5 (1.1) $(\mathrm{n}=33)$ to $10.2(0.4)(\mathrm{n}=13)$ and 11.7 (0.8) $(\mathrm{n}=11) \mu \mathrm{mol} / \mathrm{h} / \mathrm{cm}^{2}$ (table 3). Furthermore, the flux of the macromolecule HRP was even more dramatically diminished $(\mathrm{p}<0.01)$ even by four hours (to $1.6(0.2)$ from $3.8(0.5)$ $\left.\mathrm{pmol} / \mathrm{h} / \mathrm{cm}^{2}\right)$.

\section{Discussion}

Unimpeded entry of antigen into the mucosa can result in an inflammatory or immune cascade that culminates in major tissue damage and functional abnormalities. The epithelial lining of the intestine effectively acts as a regulated physiological sieve, maintaining the integrity of the barrier, and thereby acting as a first line of defence. In the present study we demonstrated for the first time that GLP-2 and a dipeptidyl peptidase IV resistant GLP-2 analogue, h[Gly $\left.{ }^{2}\right] \mathrm{GLP}-2$, significantly enhanced the barrier property of normal murine small intestine.

Early clinical observations ${ }^{21}$ and animal studies $^{22}$ suggested that an enteric form of glucagon (enteroglucagon) exerted a growth promoting influence on the mammalian intestine. In the gut, the proglucagon peptide can be cleaved into glicentin, oxyntomodulin, GLP-1, and GLP-2. GLP-2 is a 33 amino acid peptide that is generated in enteroendocrine $\mathrm{L}$ cells in the gut and whose sequence is highly conserved across mammalian species. ${ }^{22}$ This peptide has been found to increase murine total gut weight and elicit villus elongation. ${ }^{22}$ Tsai et al observed that GLP-2 did not stimulate intestinal proliferation via an effect on food consumption. ${ }^{27}$ Subsequent studies by the same workers showed that the intestinotrophic effect of GLP-2 was not gender or strain specific and was most effective when administered subcutaneously twice daily for 10 consecutive days. ${ }^{27}{ }^{28}$
The increased intestinal mucosal mass was correlated with an increase in crypt cell proliferation and reduced numbers of apoptotic cells. These observations imply that GLP-2 may directly or indirectly modulate the primary functions of the intestinal epitheliumthat is, selective transport and permeability. For instance, GLP-2 treated mice showed increased total expression of the disaccharidases maltase, sucrase, and lactase. ${ }^{23}$ In addition, acute (0.5-4 hours) low dose (pmolnmol) GLP-2 administered to rats by intravenous infusion increased glucose transport via GLUT2 in small intestinal basolateral membrane vesicles ${ }^{29}$ and via SGLT-1 in brush border membrane vesicles. ${ }^{30}$ Although data are accumulating on the effects of GLP-2 on intestinal nutrient transport, there is a paucity of information on the role of GLP-2 in the modulation of intestinal permeability.

Before consideration of the putative ability of GLP-2 to regulate intestinal permeability, we confirmed and extended previous published data showing that GLP-2 affected gut growth. We demonstrated that GLP-2 treated mice had increased intestinal weight, mucosal weight, total protein, and longer villi. In addition, our electron microscopy studies showed for the first time that the growth enhancing properties of GLP-2 also applied to individual enterocytes and their microvilli. The protease resistant analogue, $\mathrm{h}\left[\mathrm{Gly}^{2}\right] \mathrm{GLP}-2$, exerted similar and often greater effects on gut morphology than the native peptide. This may be of therapeutic relevance as it has been shown that rats are less responsive than mice to GLP-2 because of degradation by dipeptidyl peptidase IV. ${ }^{31}$

Gut segments from mice treated with GLP-2 or $\mathrm{h}\left[\mathrm{Gly}^{2}\right] \mathrm{GLP}-2$ for 10 days displayed enhanced intestinal barrier function, as demonstrated by several parameters. Conductance, under voltage clamped conditions, indicates the passive movement of ions across the epithelium mainly via the paracellular pathway. Thus the reduced conductance of tissues from GLP-2 or h[Gly $\left.{ }^{2}\right] \mathrm{GLP}-2$ treated mice indicated that the passive flow of ions had been retarded, and this was confirmed by data illustrating reduced serosal-to-mucosal flux of $\mathrm{Na}^{+}$ of approximately $35 \%$, a non-active process related mainly to the paracellular pathway. Under the conditions of our experiment, Isc was similar in both controls and GLP-2 treated mice. This result is not inconsistent with previous findings of enhanced expression of glucose transporters $^{30}$ as in our study the mucosal buffer did not contain glucose to stimulate $\mathrm{Na}^{+}$ absorption via SGLT1 (which would increase Isc).

Decreased ionic permeability does not necessarily indicate similar permeability changes for larger molecules. Consequently, we examined the mucosal-to-serosal flux of Cr-EDTA to assess the effect of GLP-2 on the uptake of luminally derived material. Because of its small size (molecular weight 360) and lipid insolubility, Cr-EDTA has been used extensively to assess paracellular permeability in patients with intestinal disorders. ${ }^{32}$ We observed a similar reduction in the flux of Cr-EDTA (about 
$35 \%$ ) across Ussing chambered-intestinal segments from mice treated for 10 days with either GLP-2 or h[Gly $\left.{ }^{2}\right]$ GLP-2. Increased length of a tighter/narrower paracellular pathway is one possible explanation for the decreased permeability after GLP-2 treatment.

In another series of experiments we tested the ability of GLP-2 to affect transepithelial movement of macromolecules, choosing HRP as a model protein. HRP is an ideal macromolecular marker as: (1) it is a $44 \mathrm{kDa}$ glycoprotein that under normal circumstances traverses the epithelium via transcytosis; and (2) intact HRP can be conveniently quantified using an enzymatic assay. ${ }^{25}$ We noted a dramatic diminution (by up to $80 \%$ ) of transepithelial HRP flux across jejunum from GLP-2 or h[Gly $\left.{ }^{2}\right]$ GLP-2 treated mice compared with controls, with h[Gly $\left.{ }^{2}\right]$ GLP-2 being more effective than GLP-2. A 50\% reduction in the area of HRP containing endosomes within enterocytes confirmed that peptide treatment decreased epithelial uptake of this macromolecule. It is possible that the increased length of the cells was responsible for a decreased rate of movement of this large molecule across the tissues. In addition, a longer period for transcytosis would provide increased opportunity for degradation of the protein by lysosomal enzymes.

To determine if the enhanced barrier function was due simply to an increased number of longer and more densely packed enterocytes, additional experiments were carried out in mice treated with $\mathrm{h}\left[\mathrm{Gly}^{2}\right] \mathrm{GLP}-2$ for four and 48 hours when, theoretically, epithelial cell growth would be negligible or minimal. Indeed, we found that there were no significant changes in any of the morphological features at four hours although both enterocyte length and microvillus length were significantly increased by 48 hours. In contrast, tissue conductance was significantly reduced at both four and 48 hours, and the flux of Cr-EDTA was also significantly decreased at both early times. These data indicate a discrepancy between the change in the length of the paracellular pathway and its permeability, and suggest that GLP-2 acts on elements involved in maintaining the integrity of epithelial tight junctions. Furthermore, the flux of HRP was more dramatically diminished (by $>50 \%$ at four hours) indicating the ability of $\mathrm{h}\left[\mathrm{Gly}^{2}\right] \mathrm{GLP}-2$ to rapidly influence epithelial cell function. As four hours was the earliest time point we examined, we do not know if effects may occur even earlier. However, direct addition of GLP-2 to tissues in Ussing chambers did not result in any significant changes in Isc or conductance within 90 minutes. Collectively, our data imply that GLP-2 and h[Gly ${ }^{2}$ GLP-2 rapidly and effectively reduce paracellular permeability in the small intestine and so would be expected to retard the uptake of small, luminally derived proinflammatory molecules of comparable size into the mucosa. In addition, decreased uptake of HRP suggests that GLP-2 would reduce uptake of foreign protein antigens with immunogenic properties.
Thus our data have shown that GLP-2 and $\mathrm{h}\left[\mathrm{Gly}^{2}\right] \mathrm{GLP}-2$ are not only growth promoting agents for intestinal mucosa but also enhance gut epithelial barrier function. This latter finding has clear implications for innate immunity. While the cellular and molecular mechanisms underlying these properties of GLP-2 remain to be defined, a number of scenarios can be postulated. Firstly, GLP-2 increases the rate of crypt cell proliferation and reduces apoptosis, ${ }^{28}$ and one group has reported ${ }^{33}$ that crypt cell apoptosis leads to increased permeability in murine epithelial cells. Modulation of tight junction form and function would affect paracellular permeability. Secondly, villus elongation could physically restrict access to the crypt region where tight junctions are more leaky than those present in the villus. ${ }^{34}$ In addition, rearrangement of the epithelial cytoskeleton (mircofilaments and microtubules) would affect the paracellular and transcellular permeation pathways. ${ }^{35}$ Further experiments in progress suggest that the mechanism involves several pathways. As a caveat to this discussion we would highlight that GLP-2 does not affect muscle thickness (Benjamin et al, unpublished data and Drucker and colleagues ${ }^{22}$ ), and consequently muscular changes cannot be responsible for altered flux across the full thickness intestinal segments used in this study. Our data with Cr-EDTA and HRP suggest that GLP-2 treatment affects both paracellular and transcellular permeability and effectively retards the entry of bioactive immunogenic molecules, of a range of sizes, into the mucosa. Therefore, the recently reported beneficial effects of $h\left[\mathrm{Gly}^{2}\right] \mathrm{GLP}-2$ in a mouse model of colitis $^{36}$ may be due, at least in part, to enhanced barrier function.

In summary, we have provided clear evidence that GLP-2 and a protease resistant analogue enhance the barrier function of the intestinal epithelium. By virtue of its intestinotrophic properties, therapeutic uses for GLP-2 have been suggested for conditions that result in villus atrophy such as short bowel syndrome $e^{37}$ and consequent to total parenteral nutrition. ${ }^{38}$ Furthermore, the research findings presented here underscore the potential role of GLP-2 therapy in combatting inflammatory disorders that are characterised by disruption of the normal barrier function of the epithelial lining of the small intestine.

The research described in this paper was supported by grants from the Medical Research Council of Canada, the Crohn's Colitis Foundation of Canada and Allelix Biopharmaceuticals Inc.

1 Bjarnason I, Macpherson A, Hollander D. Intestinal permeability: an overview. Gastroenterology 1995;108:1566-81.

2 Meddings JB. Intestinal permeability in Crohn's disease. Aliment Pharmacol Ther 1997;11(suppl 3):47-53.

3 Sartor RB. Current concepts of the etiology and pathogenesis of ulcerative colitis and Crohn's disease. Gastroenterol Clin North Am 1995;24:475-507.

4 Ma TY. Intestinal epithelial barrier dysfunction in Crohn's disease. Proc Soc Exp Biol Med 1997;214:318-27.

5 Hadfield RJ, Sinclair DG, Houldsworth PE, et al. Effects of enteral and parenteral nutrition on gut mucosal permeability in the critically ill. Am $\mathcal{F}$ Respir Crit Care Med 1995;152: ity in the $1545-8$.

6 Wallace JL. NSAID gastroenteropathy. Past, present and future. Can $\mathcal{f}$ Gastroenterol 1996;10:451-9.

7 Saunders PR, Kosecka U, McKay DM, et al. Acute stressors stimulate ion secretion and increase epithelial permeability in rat intestine. Am F Physiol 1994;267:G794-9. 
8 Go LL, Healey PI, Watkins SC, Simmons RL, Rowe MI. The effect of endotoxin on intestinal mucosal permeability
to bacteria in vitro. Arch Surg 1995;130:53-8.

9 Philpott DJ, McKay DM, Sherman P, et al. Infection of T84 cells with enteropathogenic Escherichia coli alters barrier cells with enteropathogenic Escherichia coli alters barrier
and transport functions. Am F Physiol 1996;270:G634-45.

10 Zuckerman MJ, Watts MT, Bhatt BD, et al. Intestinal permeability to ${ }^{51} \mathrm{Cr}-\mathrm{EDTA}$ in infectious diarrhea. Dig Dis Sci 1993;38:1651-7.

11 Madara JL, Stafford J. Interferon- $\gamma$ directly affects barrier function of cultured intestinal epithelial monolayers. $7 \mathrm{Clin}$ Invest 1989;83:724-7.

12 McKay DM, Croitoru K, Perdue MH. T cell-monocyte interactions regulate epithelial physiology in a co-culture model of inflammation. Am f Physiol 1996;270:C418-28.

13 Rodriguez P, Heyman M, Candalh C, et al. Tumour necrosis factor- $\alpha$ induces morphological and functional alterations of intestinal HT29 cl.19A cell monolayers. Cytokine 1995; 7:441-8.

14 Colgan SP, Resnick MB, Parkos CA, et al. IL-4 directly modulates function of a model human intestinal epithemodulates function of a model h.
lium. F Immunol 1994;153:2122-9.

15 Berin MC, Yang P-C, Ciok L, et al. Role for IL-4 in macromolecular transport across human intestinal epithelium. molecular transport across human

16 Planchon SM, Martins CAP, Guerrant RL, et al. Regulation of intestinal epithelial barrier function by TGF- $\beta 1$ Evidence for its role in abrogating the effect of a $\mathrm{T}$ cell cytokine. F Immunol 1994;153:5730-9.

17 Dignass AU, Podolsky DK. Cytokine modulation of intestinal epithelial cell restitution: Central role of transforming growth factor- $\beta$. Gastroenterology 1993;105:1323-32.

18 Peterson CA, Ney DM, Hinton PS, et al. Beneficial effects of insulin-like growth factor I on epithelial structure and function in parenterally fed rat jejunum. Gastroenterology 1996;111:1501-8.

19 Gasslander T, Permert J, Feng W, et al. Trophic effects by epidermal growth factor on duodenal mucosa and exocrine

20 Hirano $M$, Iwakiri R, Fujimoto K, et al. Epidermal growth factor enhances repair of rat intestinal mucosa damaged by oral administ

21 Gleeson MH, Bloom SR, Polak JM, et al. Endocrine tumour in kidney affecting small bowel structure, motility, and absorptive function. Gut 1971;12:773-82

22 Drucker DJ, Ehrlich P, Asa SL, et al. Induction of intestinal epithelial proliferation by glucagon-like peptide-2. Proc Nat Acad Sci USA 1996;93:7911-16.
23 Brubaker PL, Izzo A, Hill M, et al. Intestinal function in mice with small bowel growth induced by glucagon-like mice with small bowel growth induced by
peptide-2. Am 7 Physiol 1997;272:E1050-8.

24 Lowry OH, Rosebrough NJ, Farr AL, et al. Protein measurement with the folin phenol reagent. $f$ Biol Chem 1951;193:265-75.

25 Berin CB, Kiliaan AJ, Yang PC, et al. Rapid transepithelial ntigen transport: impact of sensitization and the hypersensitivity reaction. Gastroenterology 1997;113:856-64

26 Bijlsma PB, Kiliaan AK, Scholten G, et al. Carbachol, but not forskolin, increases mucosal-to-serosal transport of intact protein in rat ileum in vitro. Am f Physiol 1996;271: G147-55

27 Tsai CH, Hill M, Asa SL, et al. Intestinal growth-promoting properties of glucagon-like peptide-2 in mice. Am F Physiol 1997;273:E77-84.

28 Tsai CH, Hill M, Drucker DJ. Biological determinants of intestinotrophic properties of GLP-2 in vivo. Am $\mathcal{F}$ Physiol 997;272:G662-8.

29 Cheeseman CI, Tsang R. The effect of GIP and glucagon-like peptides on intestinal basolateral membrane hexose transport. Am 7 Physiol 1996;271:G477-82.

30 Cheeseman CI. Upregulation of SGLT-1 transport activity in rat jejunum induced by GLP-2 infusion in vivo. $A m \mathcal{F}$ Physiol 1997;273:R1965-71.

31 Drucker DJ, Shi Q, Crivici A, et al. Regulation of the biological activity of glucagon-like peptide 2 in vivo by dipeptidyl peptidase IV. Nat Biotechnol 1997;15:673-7.

32 Bjarnason I, Peters TJ, Levi AJ. Intestinal permeability: clinical correlates. Dig Dis Sci 1986;4:83-92.

33 Alnadjim Z, Koehler R, Kayali Z, et al. Crypt cell apoptosis and increased mucosal permeability induced by activated cells. Gastroenterology 1998;114:A348 (abstract).

34 Hollander D. The intestinal permeability barrier. A hypothesis as to its regulation and involvement in Crohn's disease. Scand 7 Gastroenterol 1992;27:721-6.

35 Madara JL. Loosening tight junctions-lessons from the intestine. $\mathcal{f}$ Clin Invest 1989;83:1089-94.

36 Drucker DJ, Yusta B, Bouchey RP, et al. Human $\left[\mathrm{Gly}^{2}\right]$ GLP-2 reduces the severity of colonic injury in a $\left[\mathrm{Gly}^{2}\right]$ GLP-2 reduces the severity of colonic injury in a murine model of

37 Scott RB, Kirk D, MacNaughton WK, et al. GLP-2 augments the adaptive response to massive resection in rat. Am 7 Physiol 1998;275:G911-21.

38 Chance WT, Foley-Nelson T, Thomas I, et al. Prevention of parenteral nutrition-induced gut hypoplasia by coinfusion of glucagon-like peptide-2. Am F Physiol 1997;273:G55963. 